\title{
Activated macrophages are crucial during acute PM2.5 exposure-induced angiogenesis in lung cancer
}

\author{
RUYI LI ${ }^{1}$, LIUQING YANG $^{2}$, NAN JIANG $^{3}$, FEIYUN WANG $^{2}$, PEI ZHANG ${ }^{2}$, RUI ZHOU ${ }^{1}$ and JIANGE ZHANG ${ }^{2}$ \\ ${ }^{1}$ Department of Respiratory Medicine, The Second Xiangya Hospital, Central South University, Changsha, Hunan 410011; \\ ${ }^{2}$ Innovation Research Institute of Traditional Chinese Medicine, Shanghai University of Traditional Chinese Medicine, \\ Shanghai 201203; ${ }^{3}$ Research Institute of Environmental Science, College of Chemistry and \\ Molecular Engineering, Zhengzhou University, Zhengzhou, Henan 450001, P.R. China
}

Received March 18, 2019; Accepted October 22, 2019

DOI: $10.3892 / \mathrm{ol} .2019 .11133$

\begin{abstract}
The importance of ambient particulate matter (PM2.5) in lung cancer progression is well established; however, the precise mechanisms by which PM2.5 modulates lung cancer development have not yet been determined. The present study demonstrated increased mRNA and protein expression levels of vascular endothelial growth factor in PM2.5-induced macrophages. However, no significant changes to the expression levels of angiogenic cytokines (vascular endothelial growth factor A, matric metallopeptidase 9, basic fibroblast growth factor and platelet-derived growth factor) were observed in the Lewis lung carcinoma (LLC) cell line in response to acute PM2.5 exposure. PM2.5-induced activated macrophages were revealed to upregulate angiogenic cytokine expression following the acute exposure of LLC cells to PM2.5-induced macrophage supernatant. In vivo, the pro-angiogenic and macrophage accumulation functions of PM2.5 were supported by the establishment of a polyvinyl alcohol sponge implantation mouse model. Furthermore, PM2.5 was demonstrated to increase angiogenesis and macrophage recruitment in mice that were subcutaneously injected with LLCs. These results indicated that PM2.5 increases angiogenesis, and macrophages are crucial mediators of PM2.5-induced angiogenesis in lung cancer. These findings may provide novel insights for the development of lung cancer treatment strategies.
\end{abstract}

Correspondence to: Professor Rui Zhou, Department of Respiratory Medicine, The Second Xiangya Hospital, Central South University, 139 Renmin Middle Road, Changsha, Hunan 410011, P.R. China

E-mail: zhourui2355@csu.edu.cn

Professor Jiange Zhang, Innovation Research Institute of Traditional Chinese Medicine, Shanghai University of Traditional Chinese Medicine, 1200 Cailun Road, Shanghai 201203, P.R. China

E-mail: jgzhang@shutcm.edu.cn

Key words: particle matter, macrophage, angiogenesis, lung cancer

\section{Introduction}

A number of previous studies have identified lung malignancy as one of the most common causes of cancer-associated mortality (1-3). A previous study has characterized the significant role of particulate matter (PM2.5) in increasing the occurrence of lung cancer (4). PM2.5 is a variety of airborne particulate matter that is derived from automobile exhausts, coal combustion and biomass burning (5). Previous studies have revealed that PM2.5 can induce carcinogenesis and metastasis of lung cancer via the inhibition of microRNA expression and the deregulation of tumor-associated DNA methylation $(6,7)$. However, to the best of our knowledge, the role of PM2.5 in lung cancer inflammation and angiogenesis has not been determined.

Macrophages enhance lung cancer invasion and infiltration by secreting angiogenic cytokines, including vascular endothelial growth factor A (VEGF), platelet-derived growth factor (PDGF) and basic fibroblast growth factors (bFGFs) (8). VEGF has been demonstrated to be a key regulator in angiogenesis, and is mainly produced by macrophages, tumor cells and fibroblasts $(9,10)$. Studies have demonstrated that VEGF can promote the proliferation and migration of endothelial cells by stimulating the release of angiogenic factors, binding to VEGF receptor and initiating downstream signaling pathways $(11,12)$. Additionally, PM2.5 has been indicated to activate a number of signaling pathways that promote inflammatory responses and oxidative stress in macrophages (13). Macrophage polarization has been reported to be affected by PM2.5, which can lead to the induction of the immune response and air pollutant-associated diseases (14).

As a member of the immunoglobulin superfamily, integrin associated protein, which is also known as CD47, is highly expressed in lung cancer $(15,16)$. CD47 binds to signal regulatory protein $\alpha$ (Sirp- $\alpha)$, which is located on the surface of macrophages (17). This induces the release of a signal that prevents phagocytosis of these cells by macrophages $(18,19)$. Additionally, the CD47/Sirp- $\alpha$ signaling pathway has been demonstrated to increase dendritic cell proliferation and $\mathrm{T}$ cell activation, which results in the infiltration of inflammatory cells into the tumor microenvironment (18). Furthermore, a previous study has revealed that CD47/Sirp- $\alpha$ 
is associated with the inflammatory response in the tumor microenvironment (20). Therefore, activation of macrophages and the tumor-associated CD47/Sirp- $\alpha$ signaling pathway are important in modulating lung cancer.

In the present study, it was hypothesized that macrophages may be crucial in the PM2.5-induced angiogenesis of lung cancer. To validate this hypothesis, angiogenic cytokines were measured in Lewis lung carcinoma (LLC) cells following exposure to PM2.5 or PM2.5-induced macrophage supernatant (RAW264.7). It was hypothesized that the possible mechanisms may include macrophage-induced VEGF release and activation of the CD47/Sirp- $\alpha$ signaling pathway. Therefore, VEGF and CD47/Sirp- $\alpha$ expression was determined in RAW264.7 cells following PM2.5 exposure. Subsequently, a mouse polyvinyl alcohol (PVA) sponge implantation model was established to investigate PM2.5-induced angiogenesis and macrophage accumulation in an inflammatory model. Macrophage recruitment and angiogenesis were also determined in mice that were subcutaneously injected with LLC following exposure to PM2.5 or PM2.5-induced RAW264.7 supernatant. The current study provided novel insights into the potential mechanisms of PM2.5-induced lung cancer angiogenesis.

\section{Materials and methods}

Animals. C57BL/6 mice ( $\mathrm{n}=90 ;$ 6-8 weeks old; male; $23-25 \mathrm{~g}$ ) were purchased from Silaike Laboratory Animal Co., Ltd. All mice were housed in a temperature controlled room $\left(20-24^{\circ} \mathrm{C}\right)$ on a $12 \mathrm{~h}$ light-dark cycle with unrestricted access to food and water. For all procedures performed on live mice, animals were anesthetized using sodium pentobarbital $(80 \mathrm{mg} / \mathrm{kg})$. All mice were sacrificed by cervical dislocation.

Preparation of PM2.5. PM2.5 was collected using a PM2.5 sampler (TishTE-6070D; Tisch Environmental, Inc.) at Zhengzhou University (Zhengzhou, China) between April 2016 and December 2016. PM2.5 samples were suspended in a mixture of methanol, methylene chloride and deionized water at a ratio of 8:4:1. PM2.5 was then placed into an ultrasonic bath for $30 \mathrm{~min}$. Finally, PM2.5 was obtained using ultrafiltration, and stored at $-20^{\circ} \mathrm{C}$ until subsequent use.

Cell culture. RAW264.7, LLC (ATCC ${ }^{\circledR}$ CRL-1642TM), and human non-small lung cancer H1299 and A549 cell lines were purchased from the Shanghai Institutes for Biological Sciences (http://www.cellbank.org.cn/). RAW264.7 cells were cultured in 10\% FBS and RPMI-1640 medium (both Thermo Fisher Scientific, Inc.). LLC, H1299 and A549 cells were cultured in 10\% FBS and DMEM (both Thermo Fisher Scientific, Inc.). All cell lines were supplemented with $1 \%$ penicillin-streptomycin (Thermo Fisher Scientific, Inc.) and cultured in a humidified incubator with $5 \% \mathrm{CO}_{2}$ at $37^{\circ} \mathrm{C}$.

MTT assays. Cell viability was evaluated using MTT assays. LLC, RAW264.7, H1299 and A549 cells were seeded in 96-well plates $\left(5 \times 10^{3}-1 \times 10^{4}\right.$ cells/well). Cells were subsequently exposed to different concentrations of PM2.5 (100, 200, 400, $600,800$ and $1,200 \mu \mathrm{g} / \mathrm{ml})$ at $37^{\circ} \mathrm{C}$ for $48 \mathrm{~h}$. The same volume of PBS, as the volume of PM2.5 extract, were used in the control group. A total of $20 \mu \mathrm{l}$ MTT (5 g/l) was added to each well for $4 \mathrm{~h}$, followed by the replacement of the medium with $150 \mu$ l DMSO. Optical density (OD) values were determined using a microplate reader at an absorbance of $570 \mathrm{~nm}$ (BioTek Instruments, Inc.). Cell viability was calculated based on the OD values.

Reverse transcription-quantitative PCR (RT-qPCR). LLC and RAW264.7 cells were treated with different concentrations of PM2.5 $(50,500,2,000,4,000,6,000,8,000 \mu \mathrm{g} / \mathrm{ml})$ or $500 \mu \mathrm{g} / \mathrm{ml}$ PM2.5-induced RAW264.7 supernatant for $3 \mathrm{~h}$ at $37^{\circ} \mathrm{C}$. Total RNA was isolated from cells using TRIzol ${ }^{\circledR}$ reagent (Invitrogen; Thermo Fisher Scientific, Inc.), and cDNA was synthesized using a Takara reverse transcriptase kit (for $15 \mathrm{~min}$ at $37^{\circ} \mathrm{C}$ and $5 \mathrm{~min}$ at $85^{\circ} \mathrm{C}$; Takara Biotechnology Co., Ltd.) and a LabCycler PCR instrument (SensoQuest GmbH). The resulting cDNA template was subjected to qPCR using Real Time PCR Easy ${ }^{\mathrm{TM}}$ (SYBR Green I; Takara Biotechnology Co., Ltd.) on a LightCycler ${ }^{\circledR} 96$ instrument (Roche Diagnostics), using the following conditions: Initial denaturation for $30 \mathrm{sec}$ at $98^{\circ} \mathrm{C}$, followed by 17 cycles of denaturation $(10 \mathrm{sec}$ at $\left.98^{\circ} \mathrm{C}\right)$, annealing $\left(15 \mathrm{sec}\right.$ at $72^{\circ} \mathrm{C}$; decreasing by $1^{\circ} \mathrm{C} /$ cycle $)$, and extension $\left(30 \mathrm{sec}\right.$ at $\left.72^{\circ} \mathrm{C}\right)$. This step was followed by 18 cycles of denaturation $\left(10 \mathrm{sec}\right.$ at $\left.98^{\circ} \mathrm{C}\right)$, annealing $(15 \mathrm{sec}$ at $\left.54^{\circ} \mathrm{C}\right)$, initial extension $\left(30 \mathrm{sec}\right.$ at $\left.98^{\circ} \mathrm{C}\right)$, and a final extension $\left(1 \mathrm{~min}\right.$ at $\left.72^{\circ} \mathrm{C}\right)$. The primer sequences used were as follows: VEGF-A forward, 5'-GGAGATCCTTCGAGGAGCACTT-3' and reverse, 5'-GGCGATTTAGCAGCAGATATAAGAA-3'; $\beta$-actin forward, 5'-GTGGGCCGCTCTAGGCACCAA-3' and reverse, 5'-TGGCTTTAGGGTTCAGGGGG-3'; bFGF forward 5'-AGCGGCTCTACTGCAAGAAC-3' and reverse, 5'-GCCGTCCATCTTCCTTCATA-3'; PDGF forward, 5'-CAAGACCAGGACGGTCATTT-3' and reverse, 5'-ACT TTGGCCACCTTGACACT-3'; CD47 forward, 5'-TGGTAT CCAGCAAGCCTTAG-3' and reverse, 5'-AAGACACCAGTG CCATCAAT-3'; Sirp- $\alpha$ forward, 5'-ACCACCGTGAACCCT AGTGGAA-3' and reverse, 5'-GGTGGGTGAAACTCGGAT GAAG-3'. Alterations in cytokine expression were determined by normalizing levels to those of $\beta$-actin. RT-qPCR were analyzed and fold changes were determined using the $2^{-\Delta \Delta C q}$ method (21).

ELISA. VEGF protein levels of RAW264.7 were measured in supernatant following treatment with $500 \mu \mathrm{g} / \mathrm{ml}$ PM2.5 for $12 \mathrm{~h}$ at $37^{\circ} \mathrm{C}$. VEGF protein levels were determined using a VEGF ELISA kit (eBioscience; Thermo Fisher Scientific, Inc.), which was performed according to the manufacturer's protocol. OD values were obtained at $450 \mathrm{~nm}$ in triplicate using a microplate reader (Molecular Devices, LLC).

Immunofluorescence. Sponge tissues and tumor tissues were fixed using $4 \%$ paraformaldehyde (PFA) for $24 \mathrm{~h}\left(4^{\circ} \mathrm{C}\right)$ and embedded in paraffin (5 $\mu \mathrm{m}$ sections). For immunofluorescence staining of VEGF, F4/80+, FITC-labeled lectin CD31 and $\alpha$-smooth muscle actin ( $\alpha$-SMA), sponge slides and tumor tissue slides were permeabilized with $0.3 \%$ Triton X-100 in PBS for $20 \mathrm{~min}$ at room temperature and blocked with $5 \%$ bovine serum albumin (Sigma-Aldrich; Merck KGaA) for $30 \mathrm{~min}$, then the slides were incubated with the primary antibodies at $4^{\circ} \mathrm{C}$ for $24 \mathrm{~h}$. Primary antibodies are as follows: VEGF (1:300 dilution; cat. no. sc-7269; Santa Cruz Biotechnology, Inc.), F4/80+ 
(1:350 dilution; cat. no. 14-4801-82; eBioscience; Thermo Fisher Scientific, Inc.), FITC-labeled lectin (1:350 dilution; cat. no. L9381; Sigma-Aldrich; Merck KGaA), CD31 (1:300 dilution; cat. no. ab9498; Abcam) and $\alpha$-SMA (1:300 dilution; cat. no. ab5694Abcam). Subsequently, slides were washed with PBS and then incubated with the appropriate secondary antibody at $37^{\circ} \mathrm{C}$ for $3 \mathrm{~h}$. The secondary antibodies were anti-mouse IgG (1:450 dilution; cat. no. 4410) and anti-rabbit IgG (1:450 dilution; cat. no. 4412; both Cell Signaling Technology, Inc.). The slides were stained with DAPI (Invitrogen; Thermo Fisher Scientific, Inc.) to visualize the nuclei. Finally, a fluorescence microscope with $\mathrm{x} 20$ or $\mathrm{x} 40$ objective lens (Leica microsystem $\mathrm{GmbH}$ ) was used to view the immunolabeled slides, under 5 fields of view. Immunofluorescence quantification was performed using Image J v5.0 software (National Institutes of Health).

PVA sponge implantation model. The PVA sponge implantation model was generated as described previously (22). PM2.5 was mixed with quantitative L-polylactic acid powder (PLLA; Jinan Daigang Biomaterial Co., Ltd.), to create a slow release gel, and implanted into the back of mice using a sponge. A negative control gel was created using the same amount of PLLA. Sponges were harvested after 2 weeks of implantation with either collagenase digestion for RT-qPCR, or $4 \%$ PFA fixation and paraffin embedding for FITC-labeled lectin, $\mathrm{VEGF}$, and $\mathrm{F} 4 / 80^{+}$immunofluorescence assays. In vivo experiments the control groups used the same volume of normal saline as the volume of PM2.5 extract.

Syngeneic growth of LLC cells in mice. Animals $(\mathrm{n}=4$ mice in each group) were injected subcutaneously in the right flank with $0.2 \mathrm{ml}$ PBS containing cell suspension ( $4 \times 10^{6}$ LLC cells). Tumor volumes were measured every other day, beginning 7 days after LLC cell inoculation, and calculated according to the following formula: Volume $=$ Length $\mathrm{x} \mathrm{Width}^{2} \mathrm{x} 0.5$. Alveolar macrophages of mice lungs were depleted by intratracheal application of clodronate liposomes. The liposomes were purchased from Yeasen Biotechnology Co., Ltd. Liposomally encapsulated clodronate $(5 \mathrm{mg} / \mathrm{ml}$; Yeasen Biotechnology Co., Ltd) was stored at $-80^{\circ} \mathrm{C}$ and thawed immediately prior to use. Clodronate liposomes $(50 \mu \mathrm{l})$ were prepared for intratracheal application as previously described (23). The efficiency of clodronate liposomes was evaluated using F4/80+ immunofluorescence. Intratracheal administration of saline containing PM2.5 $(320 \mathrm{mg} / \mathrm{ml})$ began at 7 days of tumor cell inoculation, and administration was carried out every 3 days. Mice were sacrificed, and tumors were harvested on the fifteenth day following LLC cell inoculation. Subsequently, tumors were either extracted for RT-qPCR or fixed with 4\% PFA and paraffin embedded for VEGF, F4/80+, CD31, and $\alpha$-SMA immunofluorescence assays. In another tumor-bearing mouse model, LLC cells were exposed to $500 \mu \mathrm{g} / \mathrm{ml}$ PM2.5-induced RAW264.7 supernatant for $3 \mathrm{~h}\left(37^{\circ} \mathrm{C}\right)$. Subsequently the LLC cells were injected subcutaneously in the right flank of the mice $(n=4)$. Tumor extraction and the following detection assays were as aforementioned.

Statistical analysis. All data are presented as the mean $\pm \mathrm{SD}$ unless otherwise specified. A total of 3 independent repeat experiments were performed. Significance was determined by one-way ANOVA followed by Tukey's post hoc test for multiple group comparisons and t-test for comparisons between two groups using SPSS v16.0 software (SPSS, Inc.). P $\leq 0.05$ was considered to indicate a statistically significant difference.

\section{Results}

Cytotoxic effect of PM2.5 on a variety of lung cancer cell lines. Cell viability is an important parameter for evaluating the impact of toxicants on cell growth. The cell viability of macrophage RAW264.7 and lung cancer H1299, LLC and A549 cell lines, following long-term exposure to different doses (100, 200, 400, 600,800 and 1,200 $\mu \mathrm{g} / \mathrm{ml}$ ) of PM2.5, was determined using MTT assays. The results indicated that PM2.5 exhibited an inhibitory effect on viability in RAW264.7, LLC, H1299 and A549 cell lines, in a dose-dependent manner (Fig. 1A).

Macrophages are crucial for acute PM2.5 exposure-induced $V E G F-A$ expression in LLC cells. The expression levels of VEGF-A, matrix metallopeptidase-9 (MMP-9), PDGF and bFGF cytokines in LLC cells were measured in response to direct exposure to $500 \mu \mathrm{g} / \mathrm{ml}$ PM2.5 for $3 \mathrm{~h}$. No significant differences were observed in the expression levels of these cytokines in the PM2.5 exposure group compared with the control LLC cells (Fig. 1B). After $3 \mathrm{~h}$ of treatment with $500 \mu \mathrm{g} / \mathrm{ml}$ PM2.5-induced RAW264.7 supernatant, the results indicated enhanced mRNA expression of angiogenic cytokines VEGF-A, MMP-9, PDGF and bFGF in LLC cells compared with cells without PM2.5-induced RAW264.7 supernatant exposure (Fig. 1C). To explore the specific mechanisms of this, RAW264.7 cells were exposed to PM2.5 and the results revealed elevated mRNA expression levels of VEGF-A in RAW264.7 cells and increased VEGF protein expression in RAW264.7 supernatant following exposure to $500 \mu \mathrm{g} / \mathrm{ml}$ PM2.5 for $12 \mathrm{~h}$ (Fig. 1D and E). CD47 mRNA expression was significantly higher in LLC cells following acute exposure to $500 \mu \mathrm{g} / \mathrm{ml}$ PM2.5-induced RAW264.7 supernatant compared with LLC cells treated with normal RAW264.7 supernatant (Fig. 1F). Sirp- $\alpha$ expression was higher in RAW264.7 cells following exposure to $500 \mu \mathrm{g} / \mathrm{ml}$ PM2.5 (Fig. 1G). To determine the concentration of PM2.5 to be used in the in vitro experiments, RAW264.7 cells were exposed to different concentrations of PM2.5 (50, 500, 2,000, $4,000,6,000,8,000 \mu \mathrm{g} / \mathrm{ml})$ for $3 \mathrm{~h}\left(37^{\circ} \mathrm{C}\right)$. The results revealed that VEGF-A mRNA expression only increased at $500 \mu \mathrm{g} / \mathrm{ml}$, which indicated that this concentration was the most suitable for further experiments (Fig. S1).

Validation of the angiogenic and macrophage accumulation effects of PM2.5 in a PVA sponge implantation mouse model. Little is known regarding PM2.5-regulated angiogenesis and macrophage accumulation in vivo. Therefore, a PVA sponge implantation mouse model, which exhibits features of monocyte/macrophage localization and microvessel formation (22), was implemented. At 14 days following subcutaneous implantation, sponges were excised and evaluated for macrophage localization, VEGF-A mRNA expression and microvessel formation. Immunofluorescence staining for VEGF, F4/80+ and lectin in sponges revealed an increase in VEGF protein 

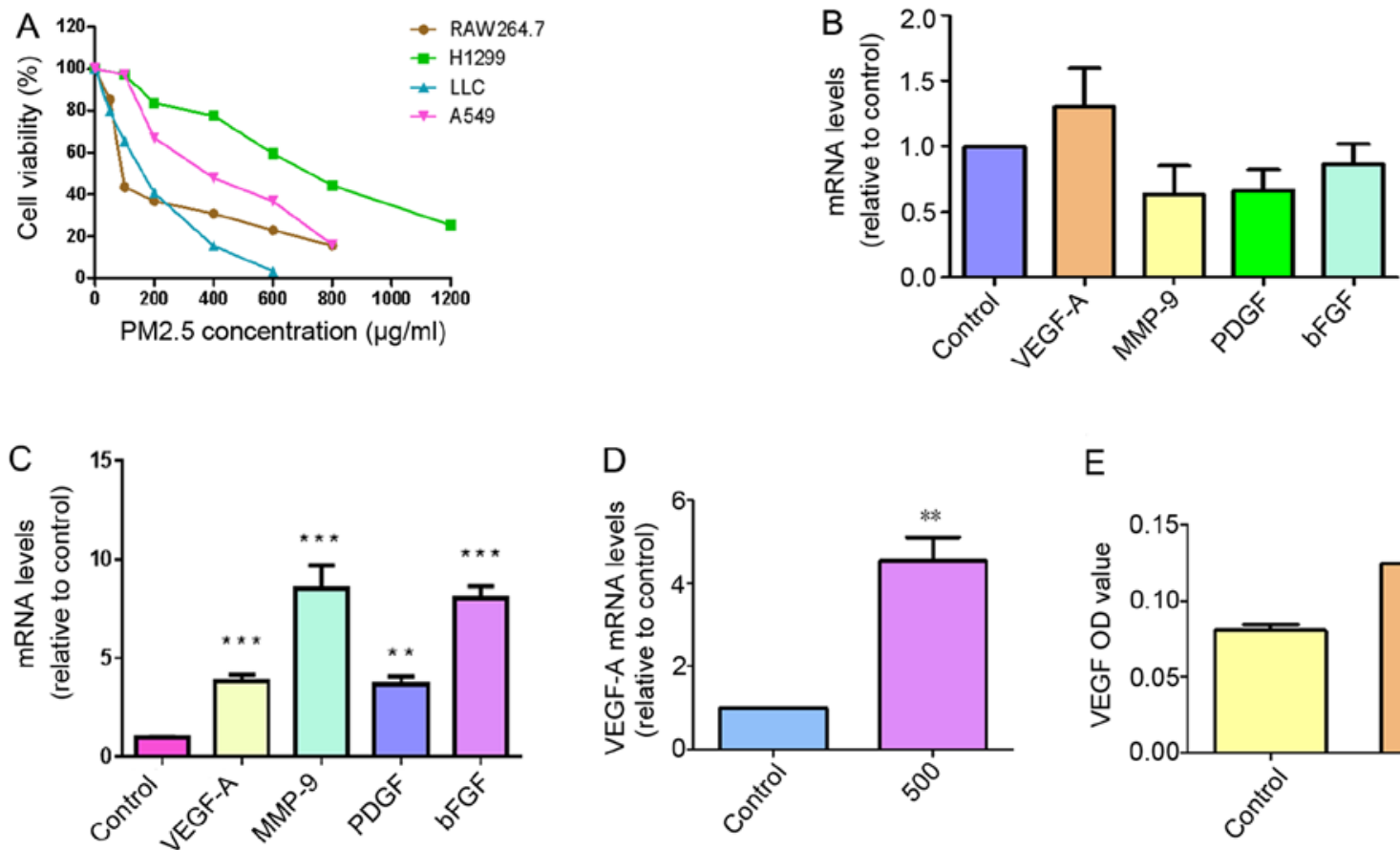

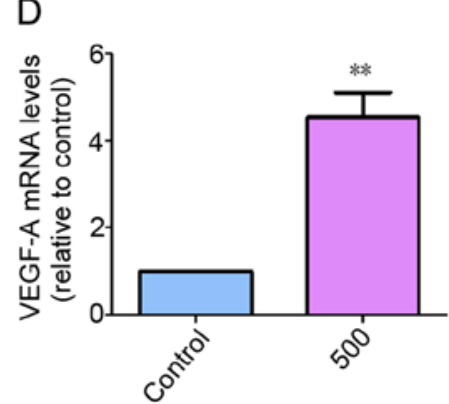

PM2.5 concentration $(\mu \mathrm{g} / \mathrm{ml})$
E

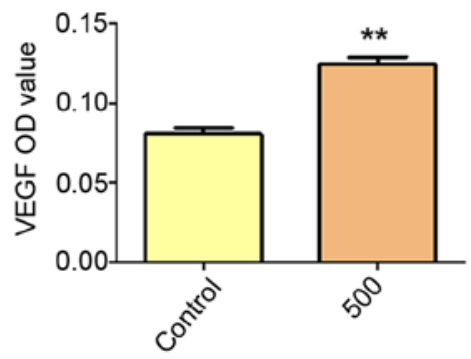

PM2.5 concentration $(\mu \mathrm{g} / \mathrm{ml})$
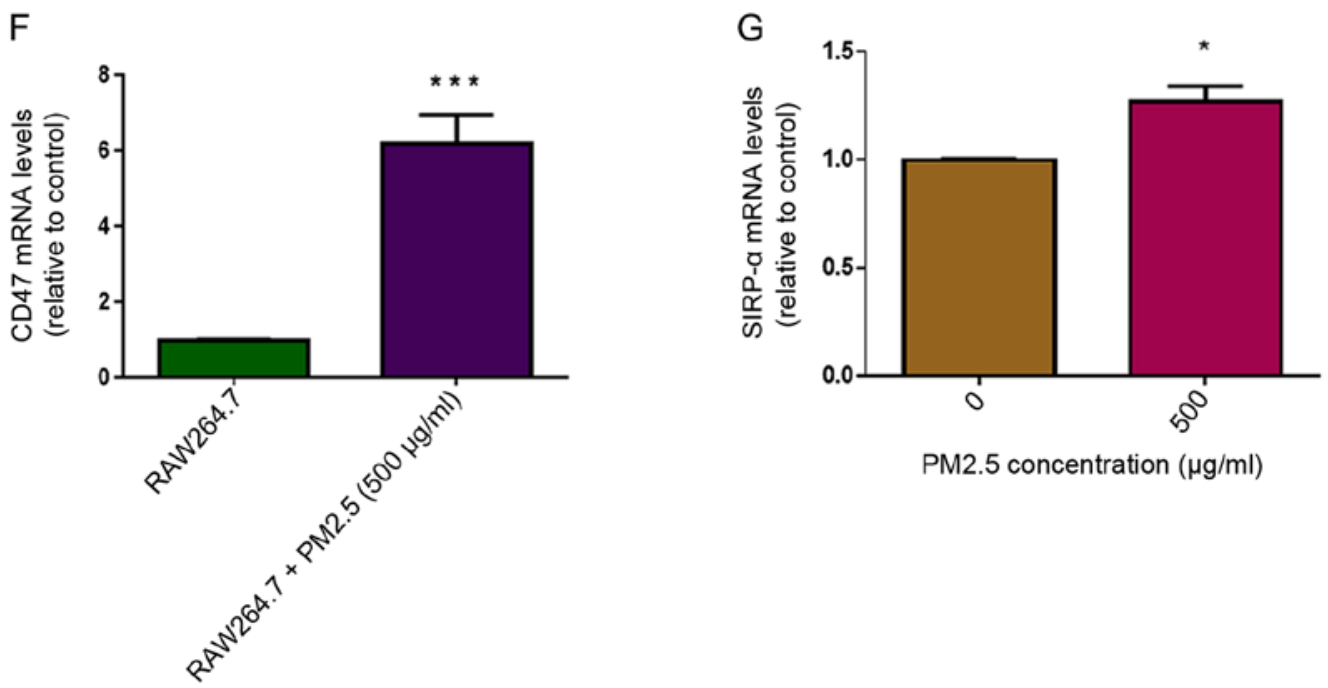

Figure 1. Role of macrophages in PM2.5-induced angiogenesis in LLC cells. (A) Cytotoxicity of PM2.5 in RAW264.7 cell, H1299 cells, LLC and A549 cells treated with different concentrations of PM2.5 for $48 \mathrm{~h}$ was measured using MTT assays $(\mathrm{n}=4)$. (B) No significantly elevated expression of several angiogenic cytokines (VEGF-A, MMP-9, PDGF and bFGF) was identified in LLC cells following direct exposure to $500 \mu \mathrm{g} / \mathrm{ml}$ PM2.5 for $3 \mathrm{~h}$. LLC cells treated without PM2.5 were used as a control. (C) Increased mRNA expression levels of angiogenic cytokines, including VEGF-A, MMP-9, PDGF and bFGF, in LLC cells was observed following exposure to $500 \mu \mathrm{g} / \mathrm{ml} \mathrm{PM} 2.5$-induced RAW264.7 supernatant for $3 \mathrm{~h}$, using reverse transcription-quantitative PCR assays. LLC cells treated without PM2.5-induced RAW264.7 supernatant were used as a control. Data are presented as the mean \pm SD of three independent experiments and were analyzed using ANOVA. ${ }^{* *} \mathrm{P}<0.01$ vs. control; ${ }^{* * *} \mathrm{P}<0.001$ vs. control. (D) Following exposure to $500 \mu \mathrm{g} / \mathrm{ml}$ PM2.5 for $3 \mathrm{~h}$, increased VEGF-A mRNA expression was observed in RAW264.7 cells. RAW264.7 cells treated without PM2.5 were used as a control. ${ }^{* *} \mathrm{P}<0.01$ vs. control. (E) Increased VEGF protein expression was detected in RAW264.7 supernatant following exposure to $500 \mu \mathrm{g} / \mathrm{ml}$ PM2.5 for $12 \mathrm{~h}$. The OD value of VEGF was determined using ELISA. RAW264.7 cells treated without PM2.5 were used as a control. ${ }^{* * *} \mathrm{P}<0.01$ vs. control. (F) CD47 mRNA expression was increased in LLC cells following exposure to $500 \mu \mathrm{g} / \mathrm{ml}$ PM2.5-induced RAW264.7 supernatant. LLC cells treated without PM2.5-induced RAW264.7 supernatant were used as a control. ${ }^{* * * *} \mathrm{P}<0.001$ vs. RAW264.7 supernatant. (G) High expression levels of SIRP- $\alpha$ were detected in PM2.5-induced RAW264.7 cells. RAW264.7 cells treated without PM2.5 were used as a control. Data are presented as the mean $\pm \mathrm{SD}$ of three independent experiments and were analyzed using a t-test. "P $<0.05 \mathrm{vs}$. PM2.5 $0 \mu \mathrm{g} / \mathrm{ml}$. PM, particle matter; LLC, Lewis lung carcinoma; VEGF-A, vascular endothelial growth factor A; MMP-9, matric metallopeptidase 9; PDGF, platelet-derived growth factor; bFGF, basic fibroblast growth factor; OD, optical density; SIRP- $\alpha$, signal regulatory protein $\alpha$.

release (indicated by VEGF; Fig. 2A), macrophage recruitment (indicated by $\mathrm{F} 4 / 80^{+}$; Fig. $2 \mathrm{~A}$ ) and microvessel density (indicated by Lectin; Fig. 2A) following exposure to $10 \mathrm{mg}$ PM2.5 (Fig. 2B). High VEGF-A mRNA expression was indicated in sponges of the PM2.5 exposure group (Fig. 2C).
Pro-angiogenesis and macrophage recruitment effects of PM2.5 in mice bearing LLC cells. A model of C57BL/6 mice bearing LLC cells was established to determine whether PM2.5 directly promoted tumor growth in mice. Furthermore, clodronate liposomes were used to decrease alveolar macrophages 
A
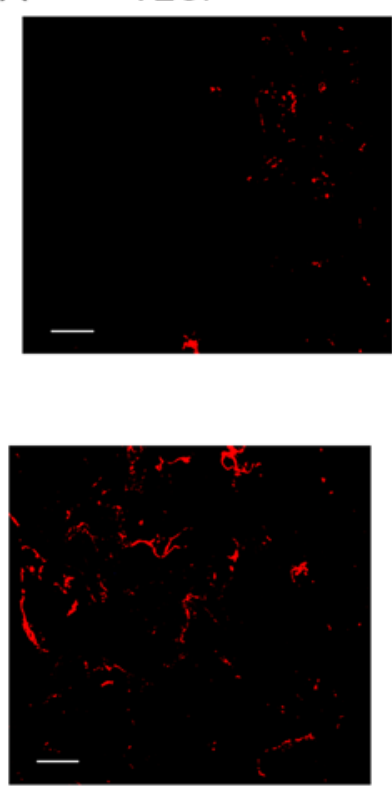

B

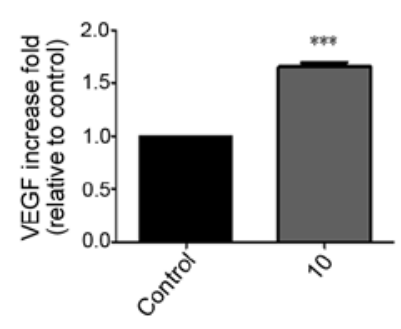

PM2.5 concentration (mg)
$\mathrm{F} 4 / 80^{+}$

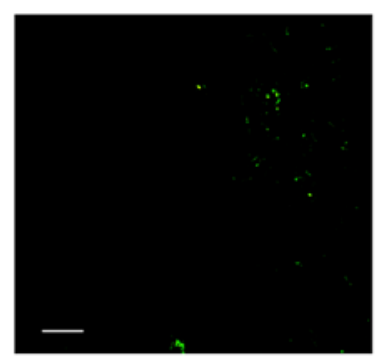

Merged

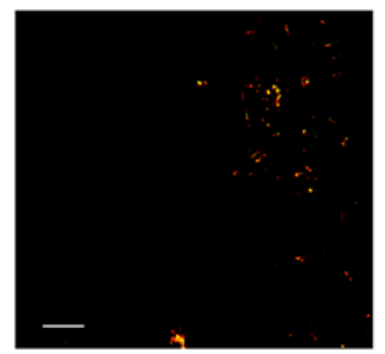

Control
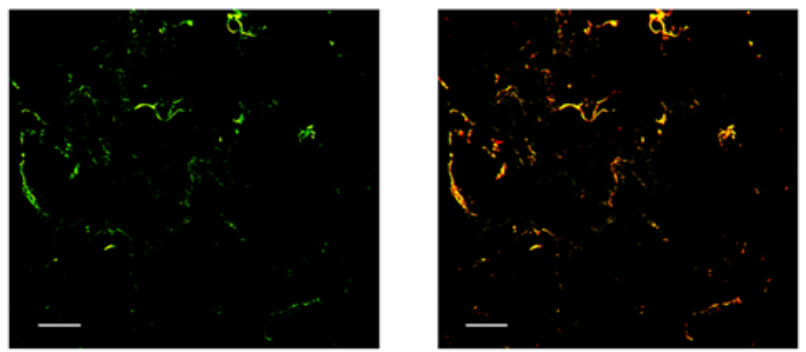

PM2.5 exposure

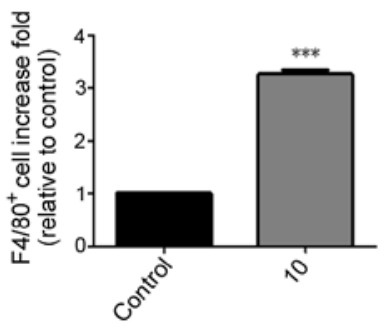

PM2.5 concentration (mg)

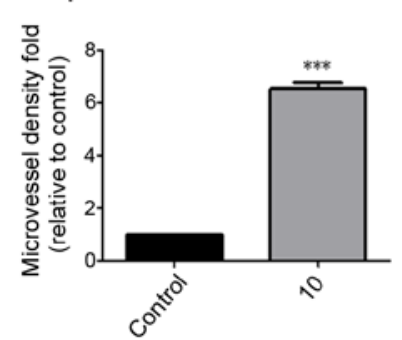

PM2. 5 concentration (mg)
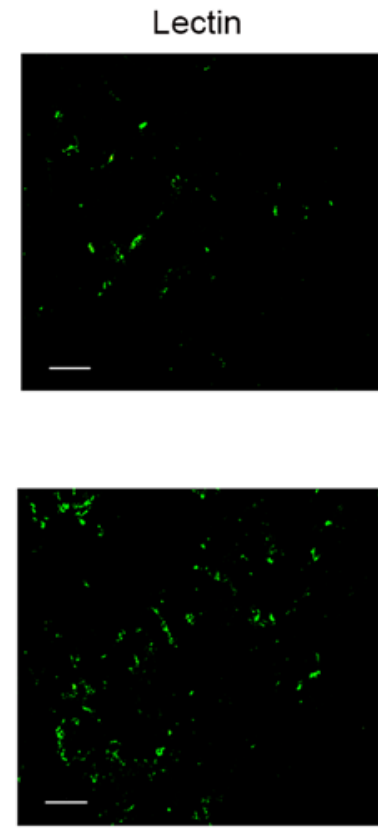

C

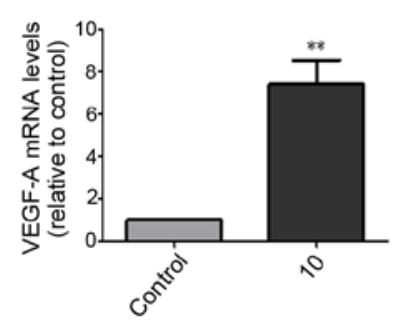

PM2. 5 concentration (mg)

Figure 2. Pro-angiogenic and macrophage recruitment effects of PM2.5 in a mouse sponge implantation model. (A) After sponges containing PM2.5 were implanted into C57BL/6 mice for 2 weeks, they were extracted and paraffin-embedded for immunofluorescence analysis. Double staining for VEGF and $\mathrm{F} 4 / 80^{+}$was conducted to detect VEGF protein release and macrophage localization in sponge tissues. Lectin staining was conducted to detect microvessel density in sponges. Sponges without PM2.5 exposure were used as a control. Increases in macrophage recruitment, VEGF protein release and microvessel density were indicated in the PM2.5 exposure group. Scale bar, $50 \mu \mathrm{m}$. (B) Immunofluorescence staining for VEGF, F4/80 ${ }^{+}$and lectin was determined using

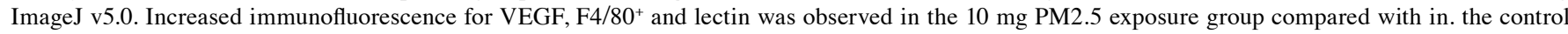
group. Data are presented as the mean $\pm \mathrm{SD}$ and were analyzed by $\mathrm{t}$-test $(\mathrm{n}=4$ mice in each group). (C) Increased VEGF-A expression was indicated in the PM2.5 exposure group compared with the control group according to reverse transcription-quantitative PCR. ${ }^{* *} \mathrm{P}<0.01 ;{ }^{* * *} \mathrm{P}<0.001$. PM, particle matter; VEGF, vascular endothelial growth factor.

in the model. This was confirmed using measurements of F4/80 immunofluorescence (Fig. 3E and G). Tumor size (Fig. 3A and B) and weight (Fig. 3C) were demonstrated to be significantly higher in the $38.4 \mathrm{mg}$ PM2.5 exposure group compared with in the control group. Tumor size and weight (Fig. 3A-C) were also decreased in the clodronate group, in which macrophage were depleted compared with that in the $38.4 \mathrm{mg}$ PM2.5 exposure group. Immunofluorescence assays of tumor tissues demonstrated increased VEGF release (Fig. 3H), macrophage recruitment (indicated by $\mathrm{F} 4 / 80^{+}$; Fig. $3 \mathrm{H}$ ) and microvessel formation (indicated by $\mathrm{CD} 31^{+}$and $\alpha$-SMA; Fig. 3H) in the PM2.5-exposed group compared with in the control group (Fig. 3I). Furthermore, once macrophages were depleted from using clodronate, the PM2.5-induced pro-angiogenic and macrophage recruitment effects were attenuated (Fig. 3H-I). Additionally, hematoxylin and eosin staining of tumor tissues indicated increased vessel formation in the PM2.5 exposure group, and vessel formation decreased in the clodronate group compared with that in the $38.4 \mathrm{mg}$
PM2.5 exposure group (Fig. 3F). Additionally, the results demonstrated that CD47 mRNA expression was increased in tumor tissues of the PM2.5 exposure group and decreased following the exposure of clodronate (Fig. 3D).

Macrophages are important in PM2.5-induced LLC tumor progression in mice. To test whether macrophages serve a role in PM2.5-induced lung cancer growth in vivo, a model of C57BL/6 mice bearing LLC cells was created. LLC cells were pre-treated with PM2.5-induced RAW264.7 supernatant for $3 \mathrm{~h}$ prior to inoculation. Tumor volume (Fig. 4A and B) and weight (Fig. 4C) were revealed to be significantly higher in the tumor tissues of mice bearing LLC cells that were treated with $500 \mu \mathrm{g} / \mathrm{ml} \mathrm{PM} 2.5$-induced macrophage supernatant. Microvessel formation (indicated by $\mathrm{CD}^{+} 1^{+}$; Fig. 4E), vascular smooth muscle cell accumulation (indicated by $\alpha$-SMA; Fig. 4E), angiogenic-associated protein release (indicated by VEGF; Fig. 4E) and macrophage recruitment (indicated by $\mathrm{F} 4 / 80^{+}$; Fig. 4E) were also 


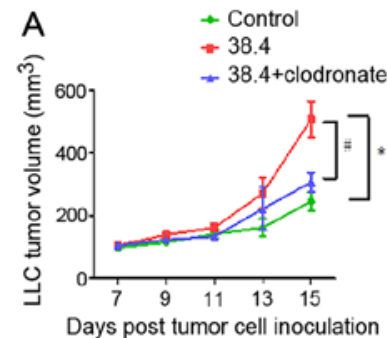

$E$

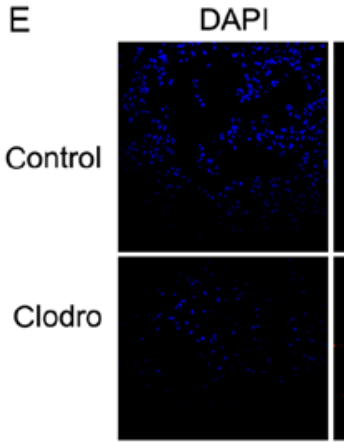

$\mathrm{F} 4 / 80^{+}$

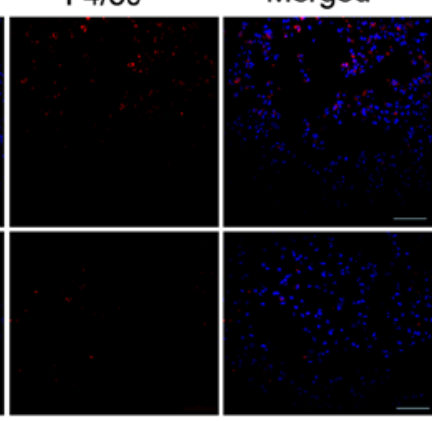

$\mathrm{H}$

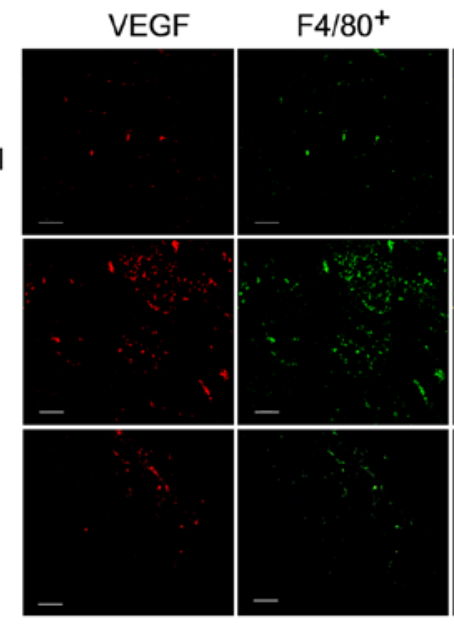

B

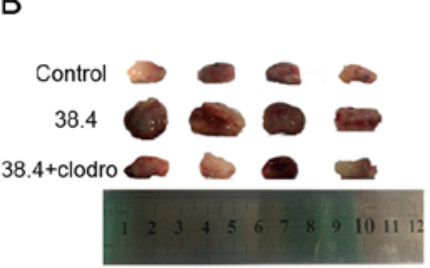

C

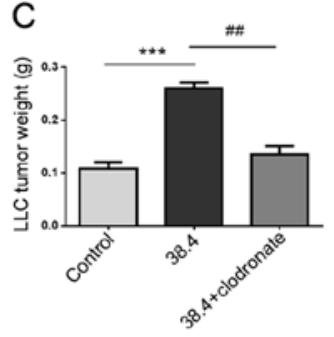

PM2.5 concentration (mg)

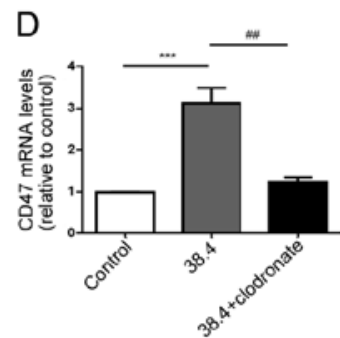

PM2.5 concentration $(\mathrm{mg})$

F Control $\quad 38.4$

38.4+clodro

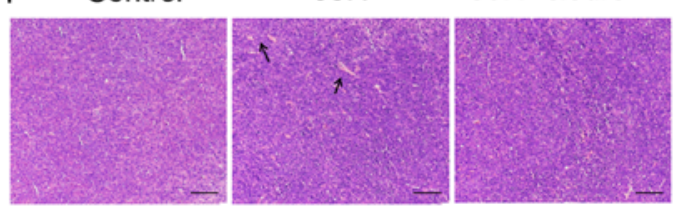

G

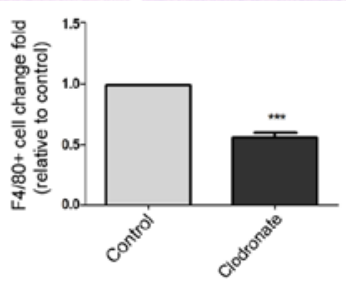

CD31

a-SMA

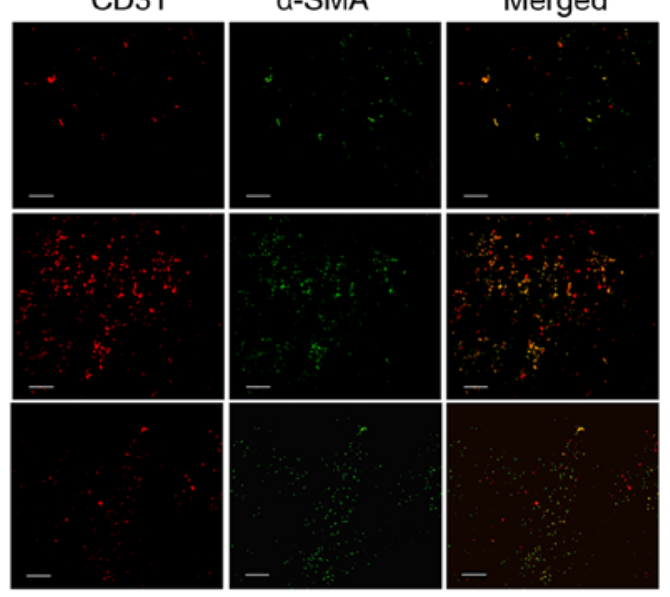

I
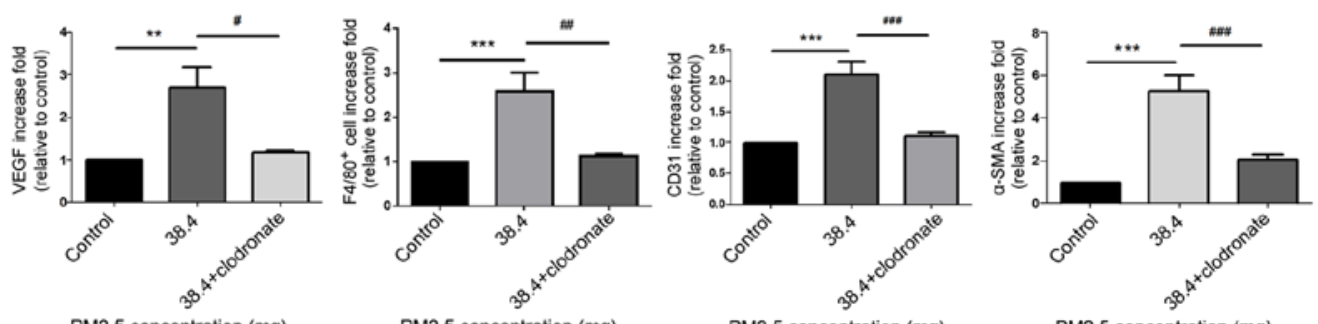

PM2.5 concentration $(\mathrm{mg})$

Figure 3. Pro-angiogenic and macrophage accumulation effects of PM2.5 in a tumor-bearing model. (A) LLC cells were inoculated into C57BL/6 mice for 15 days, and intratracheal instillation normal saline or $38.4 \mathrm{mg}$ PM2.5 was administered on days 7, 10 and 13 . Tumor length and width were measured every other day beginning 7 days after LLC cell inoculation. Tumor volume was calculated using the following formula: Volume $=$ Length $\mathrm{x}$ Width $2 \mathrm{x} 0.5$. Mice treated without PM2.5 were used as a control. ${ }^{*} \mathrm{P}<0.01 \mathrm{vs}$. control; ${ }^{\prime} \mathrm{P}<0.05 \mathrm{vs} .38 .4 \mathrm{mg}$ exposure group. (B) Tumor images were obtained after mice were euthanized on the fifteenth day of cell inoculation $(\mathrm{n}=4)$. (C) Tumor weight was highest in the $38.4 \mathrm{mg}$ PM2.5 exposure group compared with the control and macrophage depletion groups. (D) Tumor tissue CD47 mRNA expression was measured using reverse transcription-quantitative PCR. ${ }^{* * *} \mathrm{P}<0.01$ vs. control; ${ }^{\# \#} \mathrm{P}<0.01$ vs. $38.4 \mathrm{mg}$ exposure group. (E) Clodronate liposomes or normal saline were intratracheally instilled to mice. F4/80 immunofluorescence was used to test the efficiency of macrophage depletion. Scale bar, $100 \mu \mathrm{m}$. (F) Hematoxylin and eosin staining was used to observe angiogenesis in tumor tissues. Scale bar, $50 \mu \mathrm{m}$. Arrows indicated vessel. (G) Immunofluorescence quantification for F4/80 cells was performed using ImageJ v5.0 software. The clodronate group exhibited decreased macrophage accumulation in lung tissues compared with the control group. Data are presented as the mean \pm SD and were analyzed using a t-test. (H) Increased macrophage recruitment, VEGF protein release and microvessel formation were detected in response to PM2.5 exposure. VEGF and $\mathrm{F} 4 / 80^{+}$staining indicated macrophage recruitment and angiogenic protein secretion. Microvessel formation in tumor tissues was examined using CD31 and $\alpha$-SMA staining, which mark endothelial cells and vascular smooth muscle cells, respectively. Scale bar, $50 \mu \mathrm{m}$. (I) Immunofluorescence quantification for VEGF, F4/80 $0^{+}$CD31 and $\alpha$-SMA was performed using ImageJ v5.0 software. VEGF, F4/80 , CD31 and $\alpha$-SMA immunofluorescence were significantly increased in the PM2.5 exposure group compared with in the control group. Data are presented as the mean \pm SD and were analyzed by one-way ANOVA. ${ }^{* *} \mathrm{P}<0.01$ vs. control; ${ }^{* * * *} \mathrm{P}<0.001$ vs. control; ${ }^{\#} \mathrm{P}<0.05$ vs. $38.4 \mathrm{mg}$ exposure group; ${ }^{\# \#} \mathrm{P}<0.01 \mathrm{vs} .38 .4 \mathrm{mg}$ exposure group; ${ }^{\# \# \# ~} \mathrm{P}<0.001 \mathrm{vs} .38 .4 \mathrm{mg}$ exposure group. PM, particle matter; LLC, Lewis lung carcinoma; VEGF, vascular endothelial growth factor; $\alpha$-SMA, $\alpha$ smooth muscle actin; clodro, clodronate. 
A

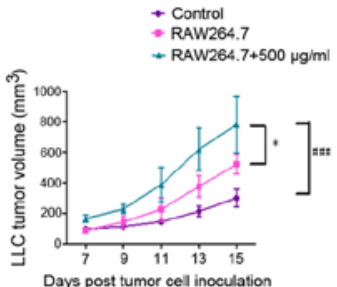

B

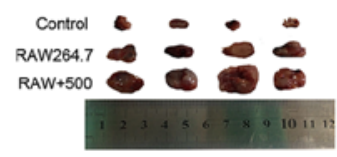

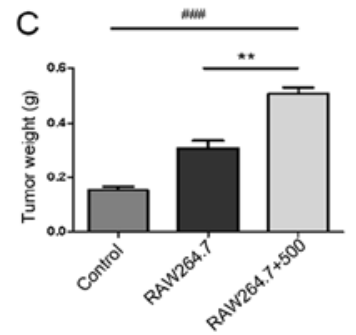

PM2.5 concentration $(\mu \mathrm{g} / \mathrm{ml})$

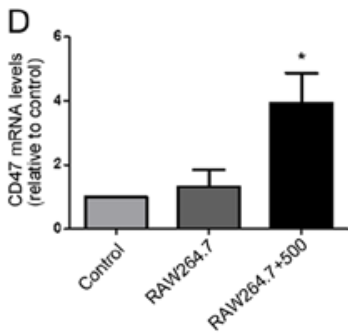

PM2.5 concentration $(\mu \mathrm{g} / \mathrm{ml})$

E
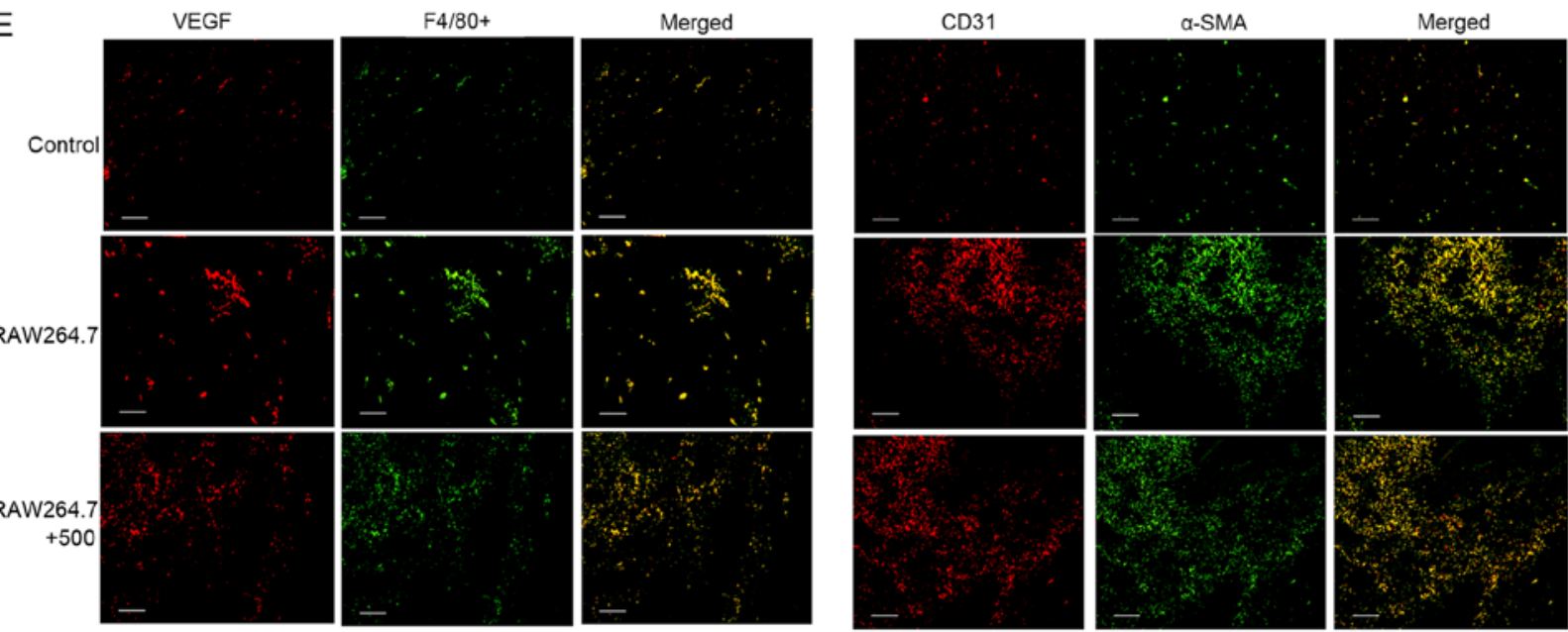

$\mathrm{F}$
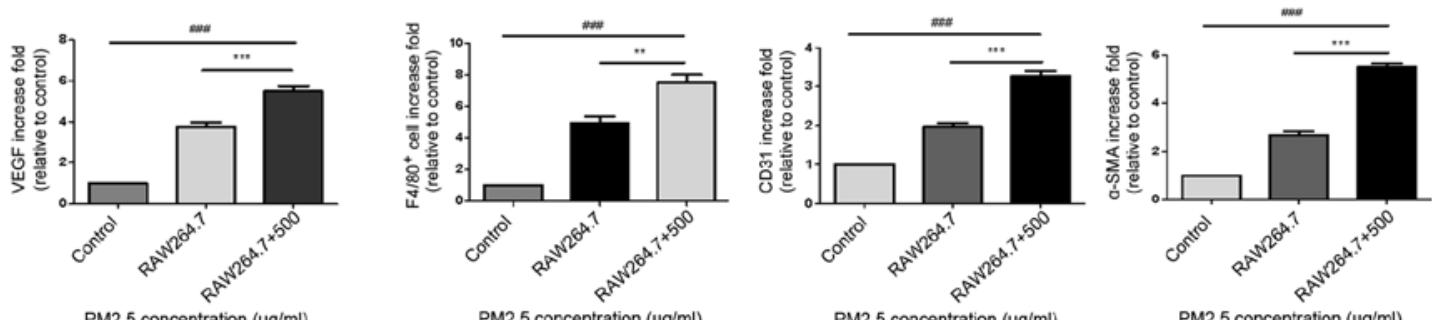

G

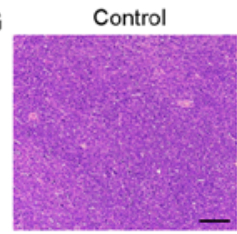

RAW264.7

RAW264.7+500
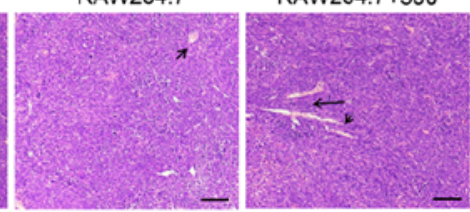

Figure 4. Macrophages mediated PM2.5-induced lung cancer angiogenesis in a tumor-bearing model. (A) LLC cells were exposed to RAW264.7 supernatant with or without PM2.5 for $3 \mathrm{~h}$ and xenografted into C57BL/6 mice for 15 days. Tumor volume was increased in the $500 \mu \mathrm{g} / \mathrm{ml}$ PM2.5-induced RAW264.7 supernatant group. ${ }^{\# \#} \mathrm{P}<0.001$ vs. control; ${ }^{~} \mathrm{P}<0.05$ vs. RAW264.7 supernatant group. (B) Tumor tissue images were obtained after mice were euthanized on day 15 of cell inoculation $(\mathrm{n}=4)$. (C) Tumor weight was significantly higher in the $500 \mu \mathrm{g} / \mathrm{ml}$ PM2.5-induced RAW264.7 supernatant group compared with the control and RAW264.7 groups. ${ }^{\# \# *} \mathrm{P}<0.001$ vs. control; ${ }^{* *} \mathrm{P}<0.01$ vs. RAW264.7 supernatant group. (D) Increased mRNA expression levels of CD47 were observed in the $500 \mu \mathrm{g} / \mathrm{ml}$ PM2.5-induced RAW264.7 supernatant group compared with in the control group. "P<0.05 vs. control. (E) Staining for VEGF, $\mathrm{F} 4 / 80^{+}, \mathrm{CD} 31$ and $\alpha$-SMA indicated the promotion of angiogenesis and macrophage accumulation in mice bearing LLC cells following exposure to $500 \mu \mathrm{g} / \mathrm{ml}$ PM2.5-induced RAW264.7 supernatant. Scale bar, $50 \mu \mathrm{m}$. (F) Immunofluorescence quantification was performed using ImageJ v5.0 software. Immunofluorescence for VEGF, F4/80+, CD31 and $\alpha$-SMA was significantly higher in the $500 \mu \mathrm{g} / \mathrm{ml}$ PM2.5-induced RAW264.7 supernatant group compared with the control and RAW264.7 groups. Data are presented as the mean \pm SD and were analyzed by one-way ANOVA ( $=4$ mice in each group). ${ }^{\sharp \# \# ~} \mathrm{P}<0.001 \mathrm{vs}$. control; ${ }^{* *} \mathrm{P}<0.01$ vs. RAW264.7 supernatant group; ${ }^{* * *} \mathrm{P}<0.001$ vs. RAW264.7 supernatant group. (G) Hematoxylin and eosin staining revealed angiogenesis in tumor tissues. Scale bar, $50 \mu \mathrm{m}$. Arrows indicate vessel. PM, particle matter; LLC, Lewis lung carcinoma; VEGF, vascular endothelial growth factor; $\alpha$-SMA, $\alpha$ smooth muscle actin.

indicated in the PM2.5-induced supernatant group (Fig. 4F). Hematoxylin and eosin staining of tumor tissues indicated angiogenesis in the PM2.5-induced supernatant group (Fig. 4G). Furthermore, the results indicated an increase in angiogenesis in the normal macrophage supernatant group, in which LLC cells were pre-treated with normal RAW264.7 supernatant prior to inoculation, compared with that in the control group. However, this was lower than that in the PM2.5-induced supernatant group. Increased CD47 mRNA expression was demonstrated in the tumor tissues of PM2.5-induced and normal macrophage supernatant groups, and the former exhibited higher CD47 expression compared with the normal macrophage supernatant group (Fig. 4D). 


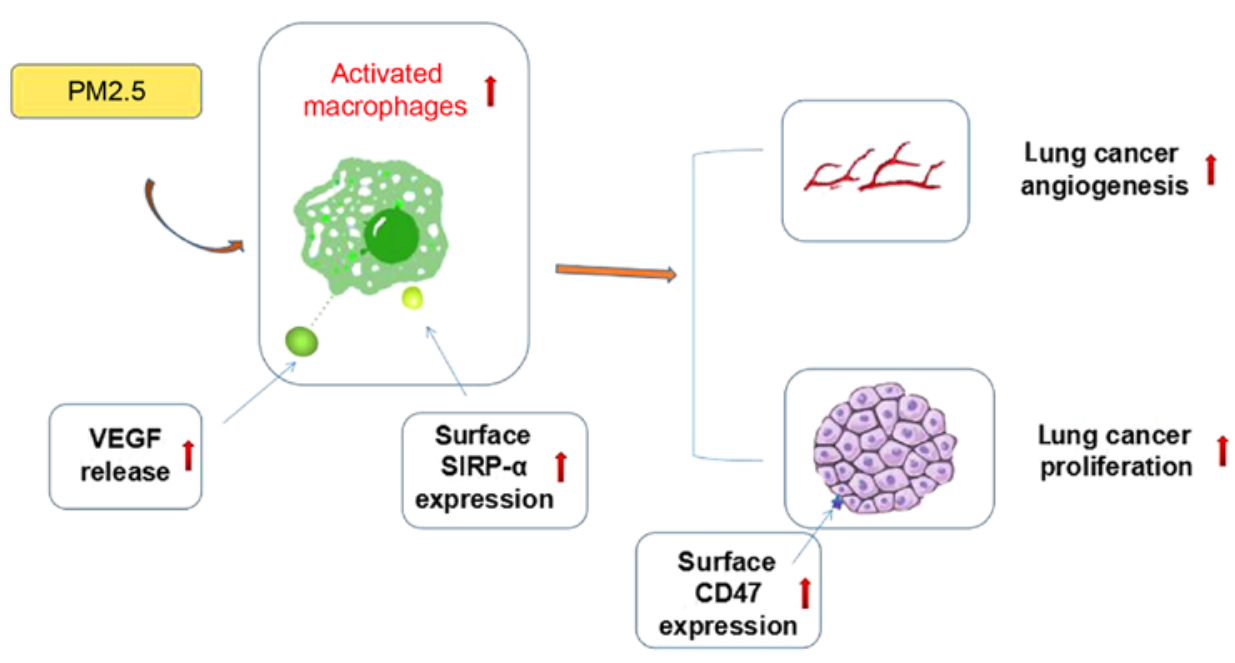

Figure 5. Activated macrophages are significant in PM2.5-induced lung cancer promotion. Angiogenic-associated cytokine release and CD47/SIRP- $\alpha$ signaling pathway activation may be involved in this process. PM, particle matter; VEGF, vascular endothelial growth factor; SIRP- $\alpha$, signal regulatory protein $\alpha$.

\section{Discussion}

Macrophages secrete a variety of inflammatory cytokines that are released into the tumor stroma and promote inflammation and angiogenesis in lung cancer $(8,24)$. A recent study has demonstrated that PM2.5 mediates macrophage autophagy via activation of PI3K/AKT/mTOR signaling (25). Another study demonstrated that crosstalk between macrophages and lung cancer cells promotes the progression of lung cancer via $\mathrm{C}-\mathrm{C}$ motif chemokine receptor 2 and $\mathrm{C}-\mathrm{X} 3-\mathrm{C}$ motif chemokine receptor 1 (26). However, to the best of our knowledge, the mechanisms associated with macrophage regulation of PM2.5-induced lung cancer promotion have not yet been determined. To assess the pro-angiogenic concentration of PM2.5 in vitro, VEGF-A mRNA expression was examined in RAW264.7 cells following short-term exposure to a variety of PM2.5 concentrations. The results revealed that VEGF-A expression was increased in RAW264.7 cells at a PM2.5 concentration of $500 \mu \mathrm{g} / \mathrm{ml}$ (Fig. S1). Only the effects of PM2.5 under acute exposure conditions were examined. Therefore, the results may change following chronic PM2.5 exposure. In the present study, no significant differences were observed between angiogenic cytokines in PM2.5-induced LLC cells. Therefore, LLC cells were exposed to PM2.5-induced RAW264.7 supernatant for $3 \mathrm{~h}$ and high expression of angiogenic cytokines was measured. These findings suggested that macrophages are important in PM2.5-mediated angiogenesis in lung cancer.

To test if this theory could be applied to in vivo models, a mouse sponge implantation model and an LLC cell xenograft mouse model were created. After implanting sponges containing PM2.5 for 2 weeks to create a model in normal mice, macrophage accumulation, microvessel formation and mRNA expression levels of VEGF were revealed to increase in PM2.5-induced sponges. Following tumor establishment in mice bearing LLC cells, it was observed that PM2.5-induced lung cancer angiogenesis and growth were closely associated with macrophage activation, since mice bearing LLC cells exposed to PM2.5 or PM2.5-induced RAW264.7 supernatant exhibited increased VEGF release, macrophage recruitment and angiogenesis in tumors. Interestingly, the present study also demonstrated that LLC cells treated with normal macrophage supernatant promoted tumor progression, and this may be associated with the production of pro-angiogenic and pro-inflammatory cytokines by macrophages in normal media. These results revealed that PM2.5 promoted angiogenesis in normal and lung cancer tissues, and macrophages were demonstrated to serve an important role in this process. In the present study, the control group in the in vitro experiments received the same volume of PBS as the volume of PM2.5 extract. The same volume of normal saline as the volume of PM2.5 extract was used as the control in the in vivo experiments.

Furthermore, the present study examined macrophage-mediated mechanisms, and the results revealed that the mRNA and protein expression levels of macrophage-secreted VEGF were increased following PM2.5 exposure. The present study only demonstrated that CD47/Sirp- $\alpha$ expression increased in in vivo and in vitro models. The specific role of the CD47/Sirp- $\alpha$ signaling pathway in PM2.5-induced lung cancer invasion requires further exploration, such as a CD47 knockout mice model. Therefore, the present study may provide a basis for studying the association between lung cancer progression and the CD47/Sirp- $\alpha$ signaling pathway. Clodronate liposomes were used to deplete macrophages in mice bearing LLC cells, which may further indicate the mediation of macrophages. Therefore, the results demonstrated that macrophages may regulate PM2.5-induced lung cancer progression by releasing VEGF and triggering the CD47/Sirp- $\alpha$ signaling pathway.

Previous studies have demonstrated that macrophages function as significant regulators in the disease-associated microenvironment and particularly in cancer $(27,28)$. The present study connected PM2.5 exposure to macrophage-mediated tumor progression, and the results demonstrated that PM2.5 may promote lung cancer in a macrophage-dependent manner.

In summary, the present study demonstrated that PM2.5 promoted lung cancer progression in vivo and in vitro, and macrophages were crucial in this process. As shown in previous studies, VEGF can induce cancer growth by promoting angiogenesis, whereas the CD47/SIRP- $\alpha$ signaling pathway is able 
to increase tumor progression by affecting the phagocytosis of macrophages and inflammatory response in the tumor microenvironment $(10,18)$. The possible mechanisms by which this occurs may include macrophage-associated cytokine release and CD47/Sirp- $\alpha$ signaling pathway activation, but further evidence is required to support this hypothesis (Fig. 5). The specific association between VEGF release and CD47/SIRP- $\alpha$ signaling pathway activation also requires further exploration. The present study may provide novel insights into the mechanisms of PM2.5-induced lung cancer progression and provides potentially novel targets for lung cancer treatment.

\section{Acknowledgements}

Not applicable.

\section{Funding}

The present study was supported by the National Natural Science Foundation of China (grant no. 81573579) and the Funding Program for New Interdisciplinary Subjects of Traditional Chinese Medicine in Shanghai (grant no. E2-F18003).

\section{Availability of data and materials}

The datasets used and/or analyzed during the present study are available from the corresponding authors on reasonable request.

\section{Authors' contributions}

RZ and JZ contributed to the design and analysis of data. RL and LY contributed to the design of the study and wrote the manuscript. NJ, FW and PZ revised the draft manuscript and performed the experiments. All authors read and approved the final manuscript.

\section{Ethics approval and consent to participate}

All animal studies were approved by the Institutional Animal Care and Use Committee of Zhengzhou University (Zhengzhou, China).

\section{Patient consent for publication}

Not applicable.

\section{Competing interests}

The authors declare that they have no competing interests.

\section{References}

1. Rimkunas VM, Crosby KE, Li D, Hu Y, Kelly ME, Gu TL, Mack JS, Silver MR, Zhou X and Haack H: Analysis of receptor tyrosine kinase ROS1-Positive tumors in non-small cell lung cancer: Identification of a FIG-ROS1 fusion. Clin Cancer Res 18: 4449-4457, 2012.

2. Ren YP, Tang AG, Zhou QX and Xiang ZY: Clinical significance of simultaneous determination of serum tryptophan and tyrosine in patients with lung cancer. J Clin Lab Anal 25: 246-250, 2011
3. Yang H, Luo J, Liu Z, Zhou R and Luo H: MicroRNA-138 regulates DNA damage response in small cell lung cancer cells by directly targeting H2AX. Cancer Invest 33: 126-136, 2015.

4. Vinikoor-Imler LC, Allen DJ and Luben TJ: An ecologic analysis of county-level PM2.5 concentrations and lung cancer incidence and mortality. Int J Environ Res Public Health 8: 1865-1871, 2011

5. Zhao YB, Gao PP, Yang WD and Ni HG: Vehicle exhaust: An overstated cause of haze in china. Sci Total Environ 612: 490-491, 2018.

6. Liu CL, Guo H, Cheng X, Shao M, Wu C, Wang S, Li H, Wei L, Gao Y, Tan W, et al: Exposure to airborne PM2.5 suppresses microRNA expression and deregulates target oncogenes that cause neoplastic transformation in NIH3T3 cells. Oncotarget 6: 29428-29439, 2015.

7. Zhou W, Tian DD, He J, Wang Y, Zhang L, Cui L, Jia L, Zhang L, Li L, Shu Y, et al: Repeated PM2.5 exposure inhibits BEAS-2B cell P53 expression through ROS-Akt-DNMT3B pathway-mediated promoter hypermethylation. Oncotarget 7: 20691-20703, 2016.

8. Chen JJ, Yao PL, Yuan A, Hong TM, Shun CT, Kuo ML, Lee YC and Yang PC: Up-regulation of tumor interleukin-8 expression by infiltrating macrophages: Its correlation with tumor angiogenesis and patient survival in non-small cell lung cancer. Clin Cancer Res 9: 729-737, 2003.

9. Koch S, Tugues S, Li X, Gualandi L and Claesson-Welsh L: Signal transduction by vascular endothelial growth factor receptors. Biochem J 437: 169-183, 2011.

10. Potente $M$ and Carmeliet P: The link between angiogenesis and endothelial metabolism. Ann Rev Physiol 79: 43-66, 2017.

11. Eichmann A and Simons M: VEGF signaling inside vascular endothelial cells and beyond. Curr Opin Cell Biol 24: 188-193, 2012.

12. Siveen KS, Prabhu K, Krishnankutty R, Kuttikrishnan S, Tsakou M, Alali FQ, Dermime S, Mohammad RM and Uddin S: Vascular endothelial growth factor (VEGF) signaling in tumour vascularization: Potential and challenges. Curr Vas Pharmacol 15: 339-351, 2017.

13. Bekki K, Ito T, Yoshida Y, He C, Arashidani K, He M, Sun G, Zeng Y, Sone H, Kunugita N and Ichinose T: PM2.5 collected in china causes inflammatory and oxidative stress responses in macrophages through the multiple pathways. Environ Toxicol Pharmacol 45: 362-369, 2016.

14. Zhao Q, Chen H, Yang T, Rui W, Liu F, Zhang F, Zhao Y and Ding W: Direct effects of airborne PM 2.5 exposure on macrophage polarizations. Biochim Biophys Acta 1860: 2835-2843, 2016.

15. Lindberg FP, Gresham HD, Schwarz E and Brown EJ: Molecular cloning of integrin-associated protein: An immunoglobulin family member with multiple membrane-spanning domains implicated in alpha v beta 3-dependent ligand binding. J Cell Biol 123: 485-496, 1993.

16. Chao MP, Alizadeh AA, Tang C, Jan M, Weissman-Tsukamoto R, Zhao F, Park CY, Weissman IL and Majeti R: Therapeutic antibody targeting of CD47 eliminates human acute lymphoblastic leukemia. Cancer Res 71: 1374-1384, 2011.

17. Murata Y, Kotani T, Ohnishi H and Matozaki T: The CD47-SIRPo signalling system: Its physiological roles and therapeutic application. J Biochem 155: 335-344, 2014.

18. Oldenborg PA, Zheleznyak A, Fang YF, Lagenaur CF, Gresham HD and Lindberg FP: Role of CD47 as a marker of self on red blood cells. Science 288: 2051-2054, 2000.

19. Jaiswal S, Chao MP, Majeti R and Weissman IL: Macrophages as mediators of tumor immunosurveillance. Trends Immunol 31: 212-219, 2010.

20. Seiffert M, Brossart P, Cant C, Cella M, Colonna M, Brugger W, Kanz L, Ullrich A and Bühring HJ: Signal-regulatory protein alpha (SIRPalpha) but not SIRPbeta is involved in T-cell activation, binds to CD47 with high affinity, and is expressed on immature CD34(+)CD38(-) hematopoietic cells. Blood 97: 2741-2749, 2001.

21. Livak KJ and Schmittgen TD: Analysis of relative gene expression data using real-time quantitative PCR and the 2(-Delta Delta $\mathrm{C}(\mathrm{T}))$ method. Methods 25: 402-408, 2001.

22. Zhang J, Modi Y, Yarovinsky T, Yu J, Collinge M, Kyriakides T, Zhu Y, Sessa WC, Pardi R and Bender JR: Macrophage $\beta 2$ integrin-mediated, HuR-Dependent stabilization of angiogenic factor-encoding mRNAs in inflammatory angiogenesis. Am J Pathol 180: 1751-1760, 2012. 
23. Tsushima Y, Jang JH, Yamada Y, Schwendener R, Suzuki K, Weder W and Jungraithmayr W: The depletion of donor macrophages reduces ischaemia-reperfusion injury after mouse lung transplantation. Eur J Cardiothorac Surg 45: 703-709, 2014.

24. Carrillo de Santa Pau E, Arias FC, Caso Peláez E, Muñoz Molina GM, Sánchez Hernández I, Muguruza Trueba I, Moreno Balsalobre R, Sacristán López S, Gómez Pinillos A and del Val Toledo Lobo M: Prognostic significance of the expression of vascular endothelial growth factors A, B, C, and D and their receptors $\mathrm{R} 1, \mathrm{R} 2$, and $\mathrm{R} 3$ in patients with nonsmall cell lung cancer. Cancer 115: 1701-1712, 2009.

25. Su R, Jin X, Zhang W, Li Z, Liu X and Ren J: Particulate matter exposure induces the autophagy of macrophages via oxidative stress-mediated PI3K/AKT/mTOR pathway. Chemosphere 167: 444-453, 2017

26. Schmall A, Altamari HM, Herold S, Kampschulte M, Weigert A, Wietelmann A, Vipotnik N, Grimminger F, Seeger W, Pullamsetti SS and Savai R: Macrophage and cancer cell cross-talk via CCR2 and CX3CR1 is a fundamental mechanism driving lung cancer. Am J Respir Crit Care Med 191: 437-447, 2015 .
27. Chen M, Zhang J, Hu F, Liu S and Zhou Z: Metformin affects the features of a human hepatocellular cell line (HepG2) by regulating macrophage polarization in a co-culture microenvironment. Diabetes Metab Res Rev 31: 781-789, 2016.

28. Wang Q, Shu C, Su J and Li X: A crosstalk triggered by hypoxia and maintained by MCP-1/miR-98/IL-6/p38 regulatory loop between human aortic smooth muscle cells and macrophages leads to aortic smooth muscle cells apoptosis via Stat 1 activation. Int J Clin Exp Pathol 8: 2670-2679, 2015.

This work is licensed under a Creative Commons Attribution-NonCommercial-NoDerivatives 4.0 International (CC BY-NC-ND 4.0) License. 